\title{
Avaliação Institucional como Mecanismo de Participação na Escola
}

\author{
Evaluación Institucional como Mecanismo de Participación en la Escuela \\ Institutional Evaluation as a School Participation Mechanism
}

\author{
Ana Luísa Antunes Rezende Tolfo ${ }^{1}$ \\ Silvana Maria Gritti²
}

\begin{abstract}
Resumo
O presente trabalho é parte de minha pesquisa de mestrado que traz como tema a participação na escola, delimitando aqui a proposta em torno da avaliação institucional como mecanismo de participação na escola. A pesquisa desenvolvida teve como objetivo identificar e compreender de que forma os instrumentos e mecanismos utilizados na avaliação institucional refletem a participação dos pais, alunos, professores, funcionários e a comunidade em geral na escola. Para tanto, nos utilizamos da metodologia da pesquisa-ação por entender que tal abordagem requer um compromisso com os sujeitos envolvidos. Dessa forma pressupomos que, para que haja a participação e que se materialize a gestão democrática, considerando uma educação de qualidade e o atendimento as necessidades das questões educacionais mostra-se imprescindível o envolvimento de cada sujeito. Ao sentir-se responsável ou parte integrante do processo de participação, os sujeitos registram sua identidade quanto membro de um grupo e buscam o envolvimento nas tarefas e trabalhos propostos para o projeto de escola que se vislumbra. Porém mobilizar a comunidade escolar nem sempre se mostra uma tarefa fácil, precisa estar bem delineada, e desenvolver mecanismos que objetivam buscar a participação como forma de transformar o meio em que se está inserido. Como forma de diagnosticar e apontar como está o processo de funcionamento da escola têm-se na avaliação institucional o caminho para oportunizar a reflexão das questões educacionais.
\end{abstract}

Palavras-chave: Avaliação Institucional. Gestão Democrática. Participação.

\section{Resumen}

El presente trabajo es parte de mi investigación de maestría que trae como tema la participación en la escuela, delimitando aquí la propuesta en torno a la evaluación institucional como mecanismo de participación en la escuela. La investigación desarrollada tuvo como objetivo identificar y comprender de qué forma los instrumentos y mecanismos utilizados en la evaluación institucional reflejan la participación de los padres, alumnos, profesores, funcionarios y la comunidad en general en la escuela. Para ello, nos utilizamos de la metodología de la investigación-acción por entender que tal enfoque requiere un compromiso con los sujetos involucrados. De esta forma presuponemos que, para que haya participación y que se materializa la gestión democrática, considerando una educación de calidad y la atención a las necesidades de las cuestiones educativas se muestra imprescindible la implicación de cada sujeto. Al sentirse responsable o parte integrante del proceso de participación, los sujetos registran su identidad como miembro de un grupo y buscan la participación en las tareas y trabajos propuestos para el proyecto de escuela que se vislumbra. Pero movilizar a la comunidad escolar no siempre se muestra una tarea fácil, necesita estar bien delineada, y desarrollar mecanismos que objetivan buscar la participación como forma de transformar el medio en que se está inserto. Como forma de diagnosticar y señalar cómo está el proceso de funcionamiento de la escuela se tiene en la evaluación institucional el camino para oportunizar la reflexión de las cuestiones educativas.

Palabras clave: Evaluación Institucional. Gestión Democrática. Participación.

\footnotetext{
${ }^{1}$ Mestranda em Educação, UNIPAMPA; Jaguarão; RS; Brasil; aninha.tolfo@ hotmail.com

${ }^{2}$ Doutora em Educação pelo Programa de Pós-Graduação em Educação da Universidade Federal do Rio Grande do Sul- UFRGS; RS; Brasil; silvanagritti@gmail.com
} 


\begin{abstract}
The present work is part of my master's research that brings as a theme the participation in the school, delimiting here the proposal about the institutional evaluation as mechanism of participation in the school. The aim of the research was to identify and understand how the instruments and mechanisms used in the institutional evaluation reflect the participation of parents, students, teachers, employees and the community in general at school. To do so, we use the methodology of action research to understand that such an approach requires a commitment to the involved subjects. In this way, we assume that, in order for participation to take place and for democratic management to materialize, considering the quality of education and meeting the needs of educational issues, it is essential to involve each subject. When they feel responsible or an integral part of the participation process, the subjects register their identity as a member of a group and seek involvement in the tasks and works proposed for the school project that is glimpsed. However, mobilizing the school community is not always an easy task, needs to be well delineated, and develop mechanisms that aim to seek participation as a way to transform the environment in which it is inserted. As a way of diagnosing and pointing out how the school's functioning process is, the institutional evaluation has the way to give the opportunity to reflect on educational issues.
\end{abstract}

Keywords: Institutional Evaluation. Democratic management. Participation.

\title{
1. Introdução
}

O presente trabalho é parte de minha pesquisa de mestrado que traz como tema a participação na escola, delimitando aqui a proposta em torno da avaliação institucional como mecanismo de participação na escola.

De acordo com Thiollent (2005), a Pesquisa-Ação não é constituída somente pela ação ou pela participação, pois com ela é possível produzir conhecimentos, adquirir experiência, contribuir com a discussão, ou fazer avançar o debate acerca das questões abarcadas. Ela está envolvida com a práxis educativa/investigativa, sendo a práxis aqui entendida como um movimento relacionado à indissociabilidade entre teoria e prática.

Entendendo que a pesquisa-ação requer um compromisso com os sujeitos envolvidos, necessariamente propicia a intervenção, onde visa proporcionar a mudança de condições, práticas ou ações. Logo, a proposta metodológica deste trabalho está fundamentada nos princípios da pesquisa-ação qualitativa, partindo da construção/elaboração do problema com o levantamento de dados da realidade onde se pretende trabalhar, utilizando-se de observações e os questionários de avaliação institucional utilizados na escola como instrumentos de registros iniciais.

Como forma de desenvolver a pesquisa, objetiva-se identificar e compreender de que forma os instrumentos e mecanismos utilizados na avaliação institucional refletem a participação dos pais, alunos, professores, funcionários e a comunidade em geral na escola. 
Lück (2006) evidencia, na gestão democrática a importância da participação, sendo estes dois termos praticamente inseparáveis, onde conceituando um certamente remete-se ao significado do outro.

Dessa forma para que haja a participação e que se materialize a gestão democrática, considerando uma educação de qualidade e o atendimento as necessidades das questões educacionais mostra-se imprescindível o envolvimento de cada sujeito. Porém mobilizar a comunidade escolar nem sempre se mostra uma tarefa fácil, precisa estar bem delineada, e desenvolver mecanismos que objetivam buscar a participação como forma de transformar o meio em que se está inserido.

Freire (2004) indicava que a escola devia realizar esforços no sentido de conseguir a maior convocação possível de todos os que convivem em torno e dentro dela, para que possam assim, se inserir em diversas ações para que haja a formação de um espírito democrático e de direitos de cidadania.

A escola precisa tomar frente às iniciativas de aproximar os integrantes da comunidade escolar, delineando caminhos para a implantação de uma gestão democrática, não só realizando convite aos participantes do processo, mas gerando condições para que os mesmos queiram e possam estar inseridos.

Em contraposição a uma gestão centralizada a participação da comunidade escolar assume força fundamental para o exercício da gestão democrática, estando nos mecanismos de participação a oportunidade de expor suas ideias, trocar informações e legitimar a capacidade decisória nas demandas escolares.

De acordo com Paro (2001), o envolvimento da comunidade escolar e comunidade em geral permite a possibilidade de controle democrático do Estado em quantidade e qualidade segundo as obrigações e responsabilidades do poder público e o interesse da sociedade na oferta de educação escolar.

Seguindo esta linha de raciocínio:

[...] a democratização da escola pública deve implicar não apenas no acesso da população a seus serviços, mas também a participação desta na tomada de decisões que dizem respeito a seus interesses [...] (PARO, 2003, p. 27).

Oportunizando que a presença da comunidade no cotidiano escolar também elabore o pensamento de participação nas decisões civis, movimento de organizações em propostas mais amplas como ações que envolvam o bairro, contribuindo no acompanhamento das políticas educacionais como forma de pressionar aos governos o encaminhamento de projetos que atendem às necessidades da educação. 


\section{Avaliação institucional como mecanismo de participação na escola}

De acordo com Lück et al., (2005), na gestão escolar, a abordagem participativa deve proporcionar o envolvimento dos sujeitos no processo de decisão, através de diferentes ações, o que requer destes o tempo, as habilidades e as experiências, de forma a enriquecer e aprimorar as ações ao longo da gestão.

Logo, a gestão democrática participativa tem como propósito a substancial participação de todos os segmentos da comunidade escolar. Sua efetivação ocorre quando as pessoas podem ter acesso às informações da escola, ao trabalho desenvolvido, de forma que os problemas identificados possam ser discutidos, avaliados, direcionados e deliberados os devidos encaminhamentos de solução e desenvolvimento da escola.

Havendo a participação geralmente os problemas são identificados claramente e facilmente são construídas as alternativas de ação, desde que os mecanismos de participação estejam acessíveis a todos, realizando o exercício de cidadania.

Libâneo (2004, p.102) nos coloca que “[...] a participação é o principal meio de assegurar a gestão democrática da escola, possibilitando o envolvimento de profissionais e usuários no processo de tomada de decisões e no funcionamento da organização escolar".

A Constituição Federal em seu artigo 205 coloca a educação como um direito de todos, assim como dever do estado e da família, e coloca a sociedade no sentido de colaborar na responsabilidade de promover e incentivar a educação como meio de desenvolvimento pleno da pessoa, a fim de prepará-la para o exercício da cidadania e atuação no trabalho (BRASIL, 1988). Assim sendo, vincula-se a gestão democrática o envolvimento e atuação da comunidade escolar como forma de colaborar para uma educação de qualidade.

A participação da comunidade escolar é parte do esforço em efetivar a democracia no ambiente escolar, estimular o processo de mudanças da administração escolar no país, aprimorando a qualidade e a eficiência da educação pública.

Não é recente a participação da comunidade nas escolas, pois de acordo com Sposito (1990), as propostas de reformas educacionais das décadas de 1920 e 30, apesar de conservadoras, defendiam a presença da comunidade na escola como forma de aquisição de hábitos saudáveis, de moral e cívica, higiene e saúde, padronizando a costumes aceitáveis na sociedade.

A partir dos anos de 1940 e 1950, a participação da comunidade na escola passou a ter um enfoque assistencialista durante o processo de urbanização e industrialização do país. 
Porém o registro dessa participação na legislação manifestou-se somente com a aprovação da Lei 4.024, de 20 de dezembro de 1961 que estabelecia as Diretrizes e Bases da Educação Nacional, onde em seu artigo 115 colocava a escola no compromisso de estimular a formação de associações de pais e professores (BRASIL, 1961).

Já nas décadas seguintes a autora coloca que a participação dos pais na escola:

[...] foi considerada tão importante para o regime autoritário, que passou a ser compulsória a partir da década de 70, mediante a regulamentação e a obrigatoriedade da criação de alguns canais, como as Associações de Pais e Mestres, tuteladas por regras burocráticas, ou seja, estabelecendo uma condição de "cidadania sob controle" [...] (SPOSITO, 1990, p.53).

Onde na legislação da época, Lei nº 5.692, de 11 de agosto de 1971 (BRASIL, 1971), registra em seu artigo 41: “A educação constitui dever da União, dos Estados do Distrito Federal, dos Territórios, dos Municípios, das empresas, da família e da comunidade em geral, que entrosarão recursos e esforços para promovê-la e incentivá-la" deixando claro de que maneira considera importante a participação na educação. E complementando a ideia no artigo 62 e respectivos parágrafos onde registra ainda a congregação de professores e pais em entidades que venham a colaborar para um eficiente funcionamento da escola:

Art. 62. Cada sistema de ensino compreenderá obrigatoriamente, além de serviços de assistência educacional que assegurem aos alunos necessitados condições de eficiência escolar, entidades que congreguem professores e pais de alunos, com o objetivo de colaborar para o eficiente funcionamento dos estabelecimentos de ensino.

$\S 1^{\circ}$ Os serviços de assistência educacional de que trata este artigo destinar-se-ão, de preferência, a garantir o cumprimento da obrigatoriedade escolar e incluirão auxílios para a aquisição de material escolar, transporte, vestuário, alimentação, tratamento médico e dentário e outras formas de assistência familiar.

$\S 2^{\circ} \mathrm{O}$ Poder Público estimulará a organização de entidades locais de assistência educacional, constituídas de pessoas de comprovada idoneidade, devotadas aos problemas sócio educacionais que, em colaboração com a comunidade, possam incumbir-se da execução total ou parcial dos serviços de que trata este artigo, assim como da adjudicação de bolsas de estudo (BRASIL, 1971).

A partir da década de 1990 o papel de Estado mínimo modificou a relação EstadoSociedade, adquirindo uma nova postura, onde os debates sociais, econômicos e educacionais ganharam força em diferentes países latinos bem como no Brasil, permitindo maior participação da sociedade na gestão de ações públicas. Onde regulamenta na Lei 9.394 de 20 de dezembro de 1996 (BRASIL, 1996) a participação dos colegiados com a função de auxiliar a Direção na administração da Escola, assim como a incumbência desta em elaborar e executar sua proposta pedagógica.

Por anos a escola assumiu uma visão centralizadora, hierárquica e autoritária, servindo a muitos o interesse de poucos, precisando com o passar do tempo e das reivindicações, 
reinventar-se dentro do contexto que a verdadeira democracia propõe, passando a gestão a estar associada

[...] ao fortalecimento da democratização do processo pedagógico, à participação responsável de todos nas decisões necessárias e na sua efetivação mediante um compromisso coletivo com resultados educacionais cada vez mais efetivos e significativos (LÜCK, 1997, p.1).

Quando o poder de decisão fica restrito, além de sobrecarregar a pessoa, cria-se uma condição centralizadora e de certo modo autoritária, o que dentro da gestão participativa, mesmo que se tenha o controle das diferentes questões da escola, na descentralização, deve ocorrer partilha das tarefas e das decisões, encarregando responsabilidades aos diferentes segmentos da comunidade, de forma a estabelecer a democracia no ambiente escolar.

Conforme Paro (2001, p.57): “A descentralização do poder se dá na medida em que se possibilita cada vez mais aos destinatários do serviço público sua participação efetiva, por si ou por seus representantes, nas tomadas de decisão".

Uma gestão descentralizada resulta em uma estrutura favorável a ação da comunidade escolar no processo de tomada de decisão e no desenvolvimento de práticas de participação, colocando a escola como um espaço de construção do processo de democracia e comprometimento com a educação, onde os sujeitos passam a envolver-se e empenhar-se no dia a dia da escola.

A aplicação do termo gestão escolar tem apresentado segundo Andrade (2004), uma mudança de postura, organização e enfoque dentro do ambiente escolar, em substituição aos modelos antigos, e em busca de maior responsabilidade e autonomia na forma de encaminhar soluções para os problemas escolares. Essa forma de gestão requer que se construam novas maneiras de se apresentar o ambiente escolar, propondo mecanismos que venham facilitar a autonomia das esferas administrativa, financeira e pedagógica da escola, comprometendo-se realmente com as atividades educativas e a participação da comunidade.

Uma melhor participação na escola requer por vezes novas organizações, repensando a cultura que está instituída e o abandono de antigas ações, constituindo metas e desenvolvendo meios que sensibilizem e fortaleçam a participação de pais, alunos, funcionários, professores e comunidade local.

$\mathrm{Na}$ gestão escolar o envolvimento da comunidade demonstra a importância dos mecanismos de participação como forma de propiciar a democratização, incentivando a atuação coletiva observando o compromisso, o respeito e a ética com os sujeitos presentes no processo. Lembrando um trecho de Freire apud (BRASIL, 2004, p.9):

Tudo o que a gente puder fazer no sentido de convocar os que vivem em torno da escola, e dentro da escola, no sentido de participarem, de tomarem um pouco o destino 
da escola na mão, também. Tudo o que a gente puder fazer nesse sentido é pouco ainda, considerando o trabalho imenso que se põe diante de nós que é o de assumir esse país democraticamente.

Logo, a criação destes mecanismos de participação faz-se necessária para a efetivação da democracia participativa, identificando aos sujeitos do que e porque estão participando, significando e definindo suas funções.

O Projeto Político Pedagógico de uma escola é um bom exemplo de participação, construção coletiva, envolvimento com o que a escola representa, a instituição de suas diretrizes, valores, e necessidades, é neste documento que a escola deve constar como um todo e detalhadamente.

Outro mecanismo de participação comum a grande parte das escolas são os colegiados, Conselhos Escolares, Grêmios Estudantis e Círculos de Pais e Mestres (em alguns lugares denominados APM). A constituição e a atuação destes colegiados efetivam participação dos diversos segmentos da comunidade escolar, como alunos, pais e profissionais em educação, e ainda definem importantes ações em auxílio à gestão da escola como a fiscalização e definição de aplicação das verbas destinadas e nos diferentes processos decisórios.

Com certeza diferentes mecanismos de participação surgem na realidade das escolas, porém estes só são elucidados na presença efetiva dos diferentes segmentos que compõe a escola, assim faz-se necessário a mobilização dos sujeitos.

Os mecanismos de participação precisam dispor de momentos de discussão desde conceitos como autonomia, cidadania, democracia e gestão escolar, assim como aspectos que possam ser considerados motivadores para a qualidade na educação.

Como forma de diagnosticar e apontar como está o processo de funcionamento da escola têm-se na avaliação institucional o caminho para oportunizar a reflexão das questões educacionais. Seu formato não é predefinido, podendo adequar-se à realidade da escola, os eixos que serão abordados e a forma como será apresentado os questionamentos.

Na realidade em que trabalho, a avaliação institucional foi estabelecida pela Secretaria de Educação e Cultura do município há pelo menos uns oito anos, com o objetivo de diagnosticar a realidade educacional como forma de oportunizar a reflexão coletiva, de maneira que todos os envolvidos realmente efetivem um maior compromisso com o trabalho da escola e com o processo de ensino-aprendizagem. Foram realizadas com as equipes gestoras da rede reuniões inicializando o assunto, discutindo e dando base para que estas chegassem à escola como multiplicadoras da proposta. Na escola o trabalho também se estendeu além do estudo, na elaboração do questionário e na forma que seria aplicado. 
Atualmente, a nova administração da Secretaria de Educação e Cultura institucionalizou um padrão de questionário para toda rede visando tabular os dados de forma mais homogenia. A escola, porém optou em manter seus questionários, observando a realidade em que está inserida e os segmentos que a compõe. A avaliação é realizada na escola antes do período de recesso escolar, geralmente no mês de julho. São propostos aos alunos, pais, funcionários e professores um questionário com questões que venham a analisar o caminhar da escola durante o primeiro semestre letivo e espaço a possíveis sugestões, ajustes e correções para o segundo semestre.

Estas questões envolvem avaliação da merenda escolar; setores como Biblioteca, Laboratório de Informática, Refeitório; limpeza e estrutura física da escola; disponibilidade e oferta de materiais pedagógicos; apoio e atendimento dos serviços da escola (funcionários, professores, direção, coordenação pedagógica e orientação) sendo classificadas em ótimo, bom, regular e insatisfatório. Ainda no questionário há espaço para as considerações e sugestões e duas perguntas: "O que você entende por participação?" e "Como é a sua participação na escola?"

Após analisados os questionários, estes são tabulados com o auxílio dos diferentes segmentos, através de representantes, e elaborada uma planilha geral com os índices de cada questionamento. Assim, é realizada a devolutiva à comunidade, discutindo e traçando meios de transformar o ambiente escolar.

A partir desses registros, propõem-se realizar momentos de estudo e discussão, tendo como temática a participação na escola.

A avaliação institucional de acordo com Lück (2012, p. 39):

[...] consiste em um processo sistemático, abrangente e contínuo de observação, coleta e análise de dados, interpretação e julgamento da realidade e práticas escolares, em seus desdobramentos e interações, tendo por objetivo contribuir para a melhoria contínua do trabalho educacional e seus resultados.

A partir dos questionários aplicados, pretende-se observar alguns fatores que possam servir como base para reflexão dos sujeitos participantes da pesquisa " [...] as quais as pessoas implicadas tenham algo a 'dizer' e a 'fazer'” (THIOLLENT, 2011, p.22).

As respostas foram analisadas em dois momentos. Primeiramente as perguntas fechadas, sendo consideradas para este trabalho as que caracterizam o tema participação na escola, com as opções de resposta: ótimo, bom, regular ou insatisfatório. E logo em seguida analisadas as perguntas abertas, que a pedido da pesquisadora foram acrescentadas ao questionário.

Dentre as perguntas fechadas considerou-se:

\begin{tabular}{|l|c|c|c|c|c|}
\hline Pergunta & Ótimo & Bom & Regular & $\begin{array}{c}\text { Insatis- } \\
\text { fatório }\end{array}$ & Não responderam \\
\hline
\end{tabular}


RELACult - Revista Latino-Americana de Estudos em Cultura e Sociedade

Revista Latinoamericana de Estudios en Cultura y Sociedad | Latin American Journal of Studies in Culture and Society V. 05, ed. especial, abr., 2019, artigo n 1218| claec.org/relacult |e-ISSN: 2525-7870

\begin{tabular}{|c|c|c|c|c|c|}
\hline $\begin{array}{c}\text { A escola procura conhecer os pais elou } \\
\text { responsáveis dos alunos? }\end{array}$ & $80,72 \%$ & $19,28 \%$ & - & - & - \\
\hline $\begin{array}{c}\text { Nesta instituição, os pais elou responsáveis } \\
\text { encontram espaços e oportunidades para } \\
\text { participarem efetivamente da vida escolar } \\
\text { de seus (suas) filhos (as)? }\end{array}$ & $87,50 \%$ & $12,50 \%$ & - & - & - \\
\hline $\begin{array}{c}\text { A escola adota procedimentos eficientes de } \\
\text { comunicação com os pais elou } \\
\text { responsáveis, alunos, funcionários } e \\
\text { professores? }\end{array}$ & $66,84 \%$ & $30,10 \%$ & $2,55 \%$ & - & $0,51 \%$ \\
\hline $\begin{array}{c}\text { Nesta escola, os pais elou responsáveis, } \\
\text { alunos, funcionários e professores } \\
\text { encontram espaços de participação e são } \\
\text { estimulados a se envolverem em projetos? }\end{array}$ & $70,92 \%$ & $25,51 \%$ & $3,06 \%$ & - & \\
\hline
\end{tabular}

Considerando o tema proposto: participação na escola, observa-se de maneira geral que todas as questões obtiveram maior porcentagem na opção "ótimo”. E analisando as questões uma a uma, observa-se que a escola necessita verificar quais procedimentos de comunicação precisam ser revistos.

Porém se analisarmos as respostas de forma mais específica, mesmo obtendo a maioria das respostas como ótima, pode-se observar uma certa oscilação entre as porcentagens desta opção como: mantêm uma média as questões conhecer os pais e/ou responsáveis dos alunos = 80,72\% e espaço de participação $=87,50 \%$; Decrescimento com relação a encontrar espaços de participação e serem estimulados a se envolverem em projetos $=70,92 \%$ e nova redução quanto a questão eficiência da comunicação $=66,84 \%$.

Cabe para refletirmos: Se as questões quanto a espaços de participação, envolvimento e conhecimento dos sujeitos foram bem avaliadas, porque a comunicação nem tanto? Para que haja participação, os sujeitos envolvidos devem estar cientes (avisados/comunicados) das propostas da escola, porém considerando as respostas obtidas, conseguem participar mesmo não estão em sua maioria devidamente informados?

Quanto às perguntas abertas: "O que você entende por participação?” e "Como é a sua participação na escola?"

Na primeira questão podemos considerar duas subdivisões de resposta:

Os que responderam considerando a disponibilidade em atender a escola em suas demandas: 


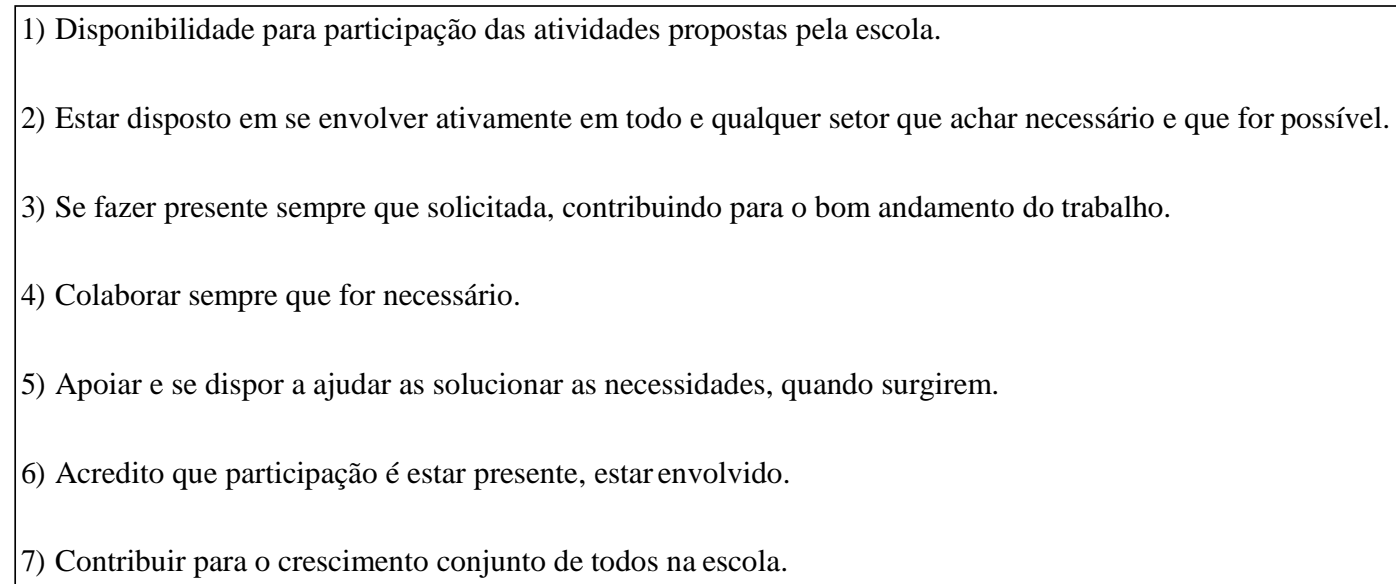

E os que procuraram caracterizá-la:

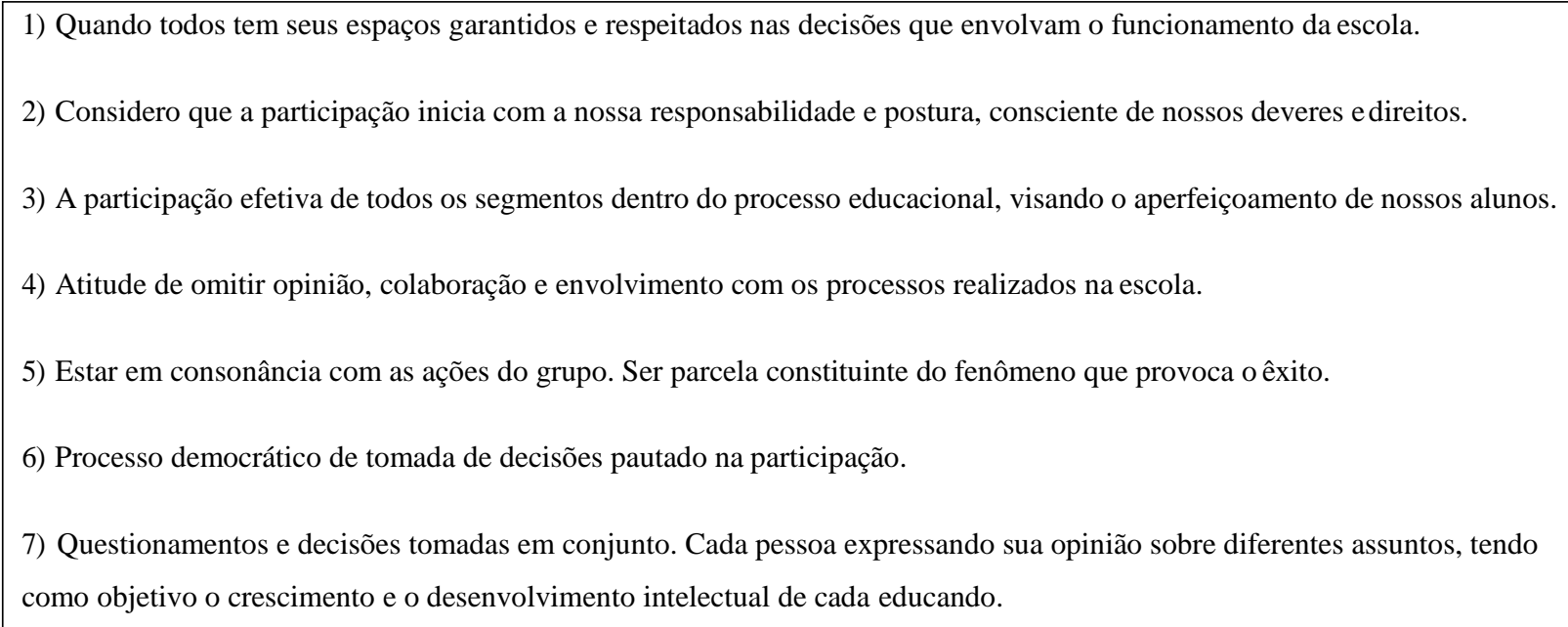

5) Estar em consonância com as ações do grupo. Ser parcela constituinte do fenômeno que provoca o êxito.

6) Processo democrático de tomada de decisões pautado na participação.

7) Questionamentos e decisões tomadas em conjunto. Cada pessoa expressando sua opinião sobre diferentes assuntos, tendo como objetivo o crescimento e o desenvolvimento intelectual de cada educando.

Na segunda questão, pode-se observar pela frequência de respostas outras duas subdivisões.

\section{Os participantes que descreveram suas funções:}

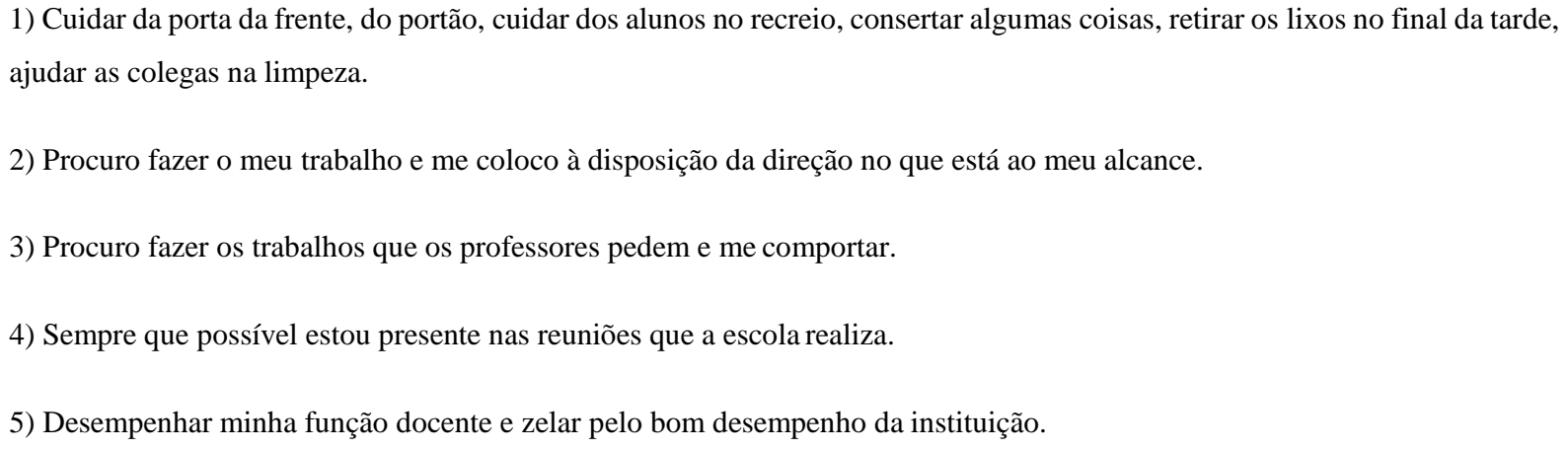

E os que procuraram classificar e/ou justificar sua participação na escola: 


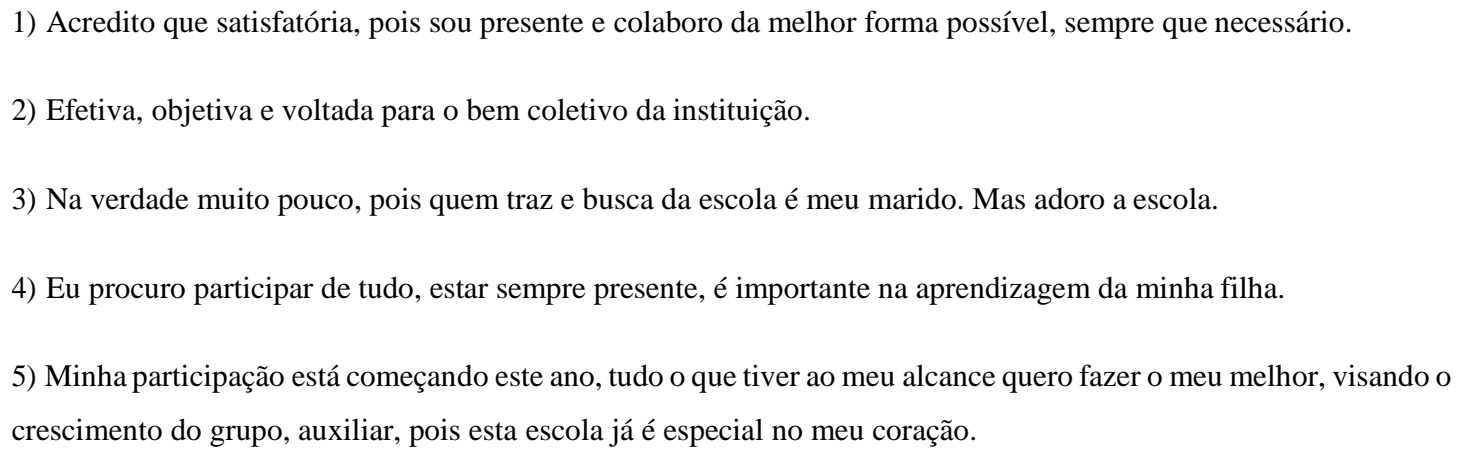

Analisando as respostas, em nenhum momento os participantes fizeram referência aos documentos legais que visam garantir a participação dos diferentes segmentos na escola, alguns utilizaram-se das palavras "processo democrático", sem muitas considerações acerca do significado e outros pautaram em suas respostas palavras como responsabilidade, postura, envolvimento, consciência, disponibilidade e tomada de decisões. Acredito que todas considerações dentro do contexto ao que o trabalho se propõe, porém sem maiores explicações.

\section{Conclusões}

Pode-se entender que o grupo participante da avaliação institucional demonstra uma ideia inicial sobre o significado da participação na escola, e atrelam suas funções como forma de participar.

Considerando que muitos participantes fizeram uso da palavra "disponibilidade", quando lhes foi perguntado como era sua participação na escola, justificaram sua frequência e a importância de estar na escola, demonstrando consideração pela instituição.

Bordignon (2004, p.307) identifica que a solução para o problema da participação está no sentimento de pertença: "Só há efetiva participação e compromisso quando se adquire a cultura do querer participar para exercer poder sobre o que lhe pertence, o que diz respeito à sua vida e ao seu futuro".

Ao sentir-se responsável ou parte integrante do processo de participação, os sujeitos registram sua identidade quanto membro de um grupo e buscam o envolvimento nas tarefas e trabalhos propostos para o projeto de escola que se vislumbra. Sendo este processo relevante na democratização da gestão escola, sendo legitimada nas ações de estar junto, do fazer coletivo, do sentimento de grupo. 


\section{Referências}

BORDIGNON, Genuíno. Gestão democrática da escola cidadã. In: FRIGOTTO, Gaudêncio; CIAVATTA, Maria (Orgs.). Ensino Médio: ciência, cultura e trabalho. Brasília, DF: MEC/SEMTEC, 2004, p.291-310.

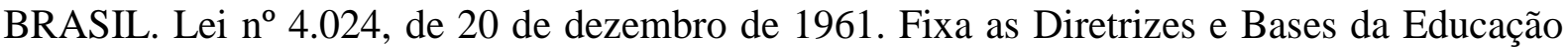
Nacional. Diário Oficial da União, Poder Legislativo, Brasília, DF, 27 dez. 1961. Seção 1 p. 11429.

Lei ${ }^{\circ} 5.692$, de 11 de agosto de 1971. Fixa Diretrizes e Bases para o ensino de $1^{\circ}$ e $2^{\circ}$ graus, e dá outras providências. Diário Oficial da União, Poder Legislativo, Brasília, DF, 12 ago. 1971. Seção 1, p.6377.

BRASIL. Constituição Federal de 1988. Promulgada em 5 de outubro de 1988. Disponível em <http://www.planalto.gov.br/ccivil_03/constituicao/constituição.htm>. Acesso em: 29 set. 2017.

Lei n. ${ }^{\circ}$ 9.394/96 de 20 de dezembro de 1996. Estabelece as diretrizes e bases da educação nacional. Diário Oficial da União, Poder Legislativo, Brasília, DF, 23 dez. 1996. Seção 1, p.27833. Disponível em: <www.planalto.gov.br/ccivil_03/leis/L9394.htm>. Acesso em: 03 out. 2017.

Conselhos escolares: Uma estratégia de gestão democrática da educação pública. Brasília: MEC/SEB, 2004.

FREIRE, Paulo. Pedagogia da autonomia: saberes necessários à prática educativa. São Paulo: Paz e Terra, 2004.

LIBÂNEO. Organização e gestão da Escola: teoria e prática. 5 ed. Goiânia: Alternativa, 2004.

LÜCK, Heloísa. A evolução da gestão educacional a partir de mudança paradigmática. Gestão em Rede, São Paulo, n.3, p.13-18, nov. 1997.

. A gestão participativa na escola. Petrópolis: Vozes, 2006 (Série: Cadernos de Gestão).

. Perspectivas da avaliação institucional da escola. Rio de janeiro: Vozes, 2012.

LÜCK, Heloísa et.al. A escola participativa: o trabalho do gestor escolar. 5 ed. Petrópolis: Vozes, 2005.

PARO, Vitor Henrique. Escritos sobre educação. São Paulo: Xamã, 2001.

Eleição de diretores: a escola pública experimenta a democracia. 2 ed. São Paulo: Xamã, 2003.

SPOSITO, Marilia Pontes. Educação, gestão democrática e participação popular. Educação e Realidade, Porto Alegre, n. 15, v. 1, p. 52-56, jan./jun. 1990.

THIOLLENT, M. Metodologia da Pesquisa-ação. 14 ed. São Paulo: Cortez, 2005.

THIOLLENT, M.. Metodologia da Pesquisa-ação. 18 ed. São Paulo: Cortez, 2011. 